\title{
Using Conceptual Developments in RFT to Direct Case Formulation and Clinical Intervention: Two Case Summaries
}

Yvonne Barnes-Holmes ${ }^{1}$, John Boorman ${ }^{2}$, Joseph E. Oliver ${ }^{3}$, Miles Thompson ${ }^{4}$, Ciara McEnteggart $^{1}$, and Carlton Coulter ${ }^{5}$

${ }^{1}$ Department of Experimental, Clinical and Health Psychology, Ghent University, Belgium ${ }^{2}$ South London \& Maudsley NHS Foundation Trust, UK, ${ }^{3}$ Department of Psychology, University College London, UK

${ }^{4}$ Department of Health and Social Sciences, Faculty of Health and Applied Sciences, University of the West of England, UK.

${ }^{5}$ NHS London

Corresponding author: Yvonne.BarnesHolmes@ugent.be

Authors' Note: The input to this article by the first and fifth authors was supported by an Odysseus Group 1 grant awarded by the Flanders Science Foundation (FWO) to Prof. Dermot Barnes-Holmes. All potentially identifying information regarding the case material has been removed or altered. 


\begin{abstract}
The current paper is part of an ongoing effort to better connect RFT with the complexities of clinical phenomena. The paper outlines two broad areas, referred to as 'verbal functional analysis' and the 'drill-down', in which we believe the basic theory is showing increasingly direct application to therapy. The paper also comprises two case summaries in which verbal functional analysis and the drill-down featured strongly in case formulation and clinical focus. Case 1 involves an adult woman who presented with paranoia, had been diagnosed with psychosis, and had an extended history of familial and other abuse. Case 2 describes a teenager who had been placed in foster care, following parental neglect. For comparative purposes and to provide exemplars of similar functional-analytic processes, both case summaries are presented in a similar format. The article attempts to illustrate how therapeutic work can be connected to the basic theory and argues that it will be important in future work to further expand these connections with ongoing developments in RFT.
\end{abstract}

Keywords: Case summaries, RFT, verbal functional analysis, the drill-down 
The current paper outlines two general approaches to psychotherapy, which we refer to as 'verbal functional analysis' and the 'drill-down', with two case summaries as supporting examples. We present these two approaches here because they have been very much motivated and directed by our knowledge of, and ongoing research activity in, Relational Frame Theory (RFT). As such, we believe that these two approaches provide good examples of how RFT is showing increasingly direct application to therapy. Before continuing, however, we think it is important to articulate three caveats to this claim. First, there is not yet empirical evidence to support the clinical utility of the two approaches we outline, nor to indicate that they are more clinically useful than alternative or existing approaches. Second, the development of our ideas is not complete, they are a beginning -- but they are at a stage where we think they are worth sharing, based primarily on discussions with colleagues, clinical supervision, direct work with clients, workshops, and as noted above our ongoing research activity. Third, these ideas did not emerge directly from recent developments in the basic science of RFT (such as those outlined in the current volume or elsewhere), and indeed the casework described here was conducted some years prior to these developments.

We should emphasize that we do not consider what we present in the current paper to be 'new' or 'different' from Acceptance and Commitment Therapy (ACT) as it was originally articulated (Hayes, Strosahl, \& Wilson, 1999). In some ways what we present here reflects how the first author was trained to do ACT. This training commenced in 1998 before the publication of the first ACT book and in the context of the writing of the first RFT book. At that time, the scientific model for ACT was not the hexaflex, but in many ways, at least from the perspective of the first author, it was RFT. It was almost five years later when the hexaflex was proposed as a model for ACT and, as argued elsewhere, a drift between RFT and ACT began (Barnes-Holmes, Barnes-Holmes, Hussey, \& Luciano, 2016). In this sense, what is presented here is not new, but old. In other words, the original therapeutic model for ACT, at 
least as it was taught in the mid to late 1990s, was largely functional-analytic, as applied to human verbal behavior (with "verbal" redefined, in the behavioral tradition, by RFT). In our view, the relationship between ACT and the ongoing development of RFT, as presented in the current article, has unfolded organically, and what we present here is simply an extension of this dialectic between theory and practice.

We recognize that others have recently attempted to present ACT largely in existing RFT terms with little appeal to the hexaflex or any of the middle-level concepts contained within it (e.g., Torneke, 2010). And yet others have very recently attempted to directly apply RFT concepts to psychotherapy, although they introduced new middle-level terms to RFT itself (Villatte, Villatte, \& Hayes, 2015). While there is clearly value in these approaches, and there will obviously be considerable overlap in this work and ours, we do believe that we are developing a different approach to what is expressed elsewhere. Rather than applying RFT as it was articulated in the 2001 book (Hayes et al., 2001) and/or adding new middle-level terms to the basic theory, we are attempting to extend RFT to psychotherapy without introducing new middle-level terms. Such an extension is an aspiration to work towards, but we are some way from reaching that aspired goal. Nevertheless, we felt it appropriate to share where we are at on that journey in the context of the current volume on conceptual developments in RFT.

\section{Overview of the Current Paper}

The current paper argues that the concept of verbal functional analysis, as well as the drill-down, highlights key ways in which RFT can be used to guide case formulation and intervention in clinical practice. For illustrative purposes, the paper comprises two case summaries. It is important to emphasize that, at the time of writing, both cases were incomplete. Hence, our intention is not to present a finished piece of work or a comprehensive illustration of verbal functional analysis and the drill-down in action. However, both 
therapists involved with the cases believed that these approaches offered a valuable means of understanding their clients' problems and directing their clinical intervention in an effective manner.

For the current paper, we selected two very different, but equally complex, cases. Case 1 involves an adult woman who presented with paranoia, had been diagnosed with psychosis, and had an extended history of familial and other abuse. In contrast, Case 2 describes a teenager who had been placed in foster care, following parental neglect. For clarity and comparison, we have structured the case summaries along similar lines. That is, both cases comprise: a brief review of functional-analytic approaches to the topic if available; referral circumstances; early history; verbal functional assessment; and therapeutic directions based on verbal functional analyses. Throughout the case summaries, we provide specific examples of clients' own words, therapist statements, and supervisor questions or suggestions. Before we present the two cases, we will first outline how we define verbal functional analysis and the drill-down in some detail.

\section{Verbal Functional Analysis}

At this point, we should be clear in defining functional analysis to mean a basic science or application of that science that focuses on operant contingencies and behavioral principles more generally in attempting to both assess and treat maladaptive behavior. In contrast, a verbal functional analysis focuses on the functions of stimuli and responses that possess properties defined as verbal within RFT. In conducting a verbal functional analysis, we typically, but not necessarily, operate at the level of complex relational networks, rather than specific relational frames. Of course, specific instances of framing may be of particular clinical interest (the case summaries contain examples) that may need to be targeted directly. In our experience, however, conducting verbal functional analyses of relational networks and their functions generates a sound working understanding of a client's behavior. Working at 
the level of relational networks also appears to offer direction on how these networks can be altered to create broad and flexible repertoires of relational responding, where this appears beneficial. During the course of therapy, specific verbal stimuli may be identified as participating in complex relational networks that generate narrow and inflexible responses. For example, the word "shame" (or more precisely the relational networks in which it participates) may elicit what appear to be subtle defensive reactions on behalf of the client, such as turning their face away, putting their head down, and even at times questioning the value of the therapy. As a result, the therapist may identify the verbal stimulus "shame" as having important functional properties for the client's behavior in and beyond therapeutic interactions, and it is these broad properties, and the relational networks in which they participate, that the therapist seeks to analyze (i.e., a verbal functional analysis).

Before continuing, it seems useful to outline the two main ways in which we use verbal functional analysis in therapy. Specifically, 1. conducting a verbal functional assessment; and 2. helping clients to verbally track (see below) the sources of behavioral control as a core relational skill.

\section{Verbal Functional Assessment}

Clients often come into therapy asserting themselves to be depressed, anxious, confused, worried, addicted, in marital difficulty, etc., which in a sense they are, because these are exactly the relational networks that the wider culture has established for, and with, them. Although categorizing and evaluating oneself in these ways may be painful and distressing, labels such as "depressed” may also have functions of safety, justification, comfort, and so on. As such, these verbal stimuli/responses have appetitive as well as aversive functions. 
In conducting a verbal functional assessment, we often think in terms of a distinction between less and more aversive relational networks in which the deictic- $\mathrm{I}^{1}$ participates. That is, the less aversive networks have dominant approach or S+ functions (similar to moving toward something), while the more aversive networks have dominant avoidance or Sfunctions (similar to moving away from something). This distinction has some overlap with distinctions suggested by Polk and Schoendorff (2014, see also Hayes et al., 1999, Hayes, Strosahl, \& Wilson, 2012; and Strosahl, Robinson, \& Gustavsson, 2012).

Now consider a client who comes into therapy with problems surrounding anger. Categorizing himself as "angry", although itself distressing, may facilitate avoidance of a more complex long-established issue, such as fear of rejection. Verbal functional assessment allows the therapist to separate out the $\mathrm{S}+$ and $\mathrm{S}$ - functions of this type of self-labeling. For example, "angry" may have more positive emotional functions than "rejected". Indeed, by describing himself as "angry", this client enables himself to avoid the more accurate (functionally speaking) description of his behavior as involving fear of rejection. To simplify using our example, we might refer to 'angry' and related self-evaluations as the S+ networks (with both aversive and appetitive functions), while referring to 'rejected' as the S- networks (with largely aversive functions). Relatively speaking, this makes it possible that the client's engagement with the $\mathrm{S}+$ networks actually serves to reinforce avoidance of the S- networks. In therapy, we use verbal functional assessments to guide our first steps toward dealing with the $\mathrm{S}+$ (e.g., angry) networks, because clients engage with these more readily, and thus the therapist's move in this direction will seem less confrontational. We are nonetheless cautious that engagement with $\mathrm{S}+$ networks likely continues to facilitate avoidance of the S- networks.

\footnotetext{
${ }^{1}$ We use the term deictic-I to refer to the verbal self which emerges from a history of arbitrarily applicable relational responding that typically involves learning to respond appropriately to self-referential terms (e.g., "I", "myself", "me").
} 
We then orient much more carefully toward the S- networks, where client defense and challenges to the therapeutic relationship are most likely. In order to harness the behavioral 'momentum' previously established in the therapeutic interactions surrounding the S+ networks (during the verbal functional assessment), the therapist uses verbal functional analyses to establish causal or if-then relations between these two sets of networks. Returning to the example above, the therapist might say something like, "Being angry must make it hard for people to get close to you". For the client, this statement relates the S+ and S- networks for the first time, perhaps facilitating a transfer of the less aversive functions of the 'angry' networks to the more aversive ('rejection') networks, in so far as the client becomes more willing to talk about rejection. To further this move, the therapist might say, for example, "What if rejection lay at the end of this line of anger? How much more angry will you get if you push loved ones away? What if being angry could cause this to happen? If you had to choose between being angry and being rejected or alone, which would you choose?"

Overall therefore, the primary purpose of verbal functional assessment is to identify verbal stimuli or responses that participate in specific relational networks for the client that possess, broadly speaking, approach and avoidance functions. Doing so facilitates establishing a strong therapeutic relationship that allows the therapist to focus on issues that may be highly sensitive for the client, and which if broached too early in therapy could undermine the relationship. In a more general way, getting the client to engage with issues they have tended to avoid is important for moving toward building the psychological flexibility required for what we describe in the next section as verbally tracking sources of behavioral control.

\section{Verbally Tracking Sources of Behavioral Control as a Core Relational Skill}


We believe that an individual's ability to verbally track $^{2}$, in an accurate and ongoing manner, the sources of control over their own behavior (internal and external) is foundational in establishing what we loosely describe as a sense of self. This overlap between behavior and the sources of control is illustrated in the intersection between the circles in the Venn diagram in Figure 1. Using more technical language, we would say that clients show deficits in the ability to relate the deictic-I, and the relational networks in which it participates, to the networks of events that functionally relate in some causal manner to the deictic-I itself.

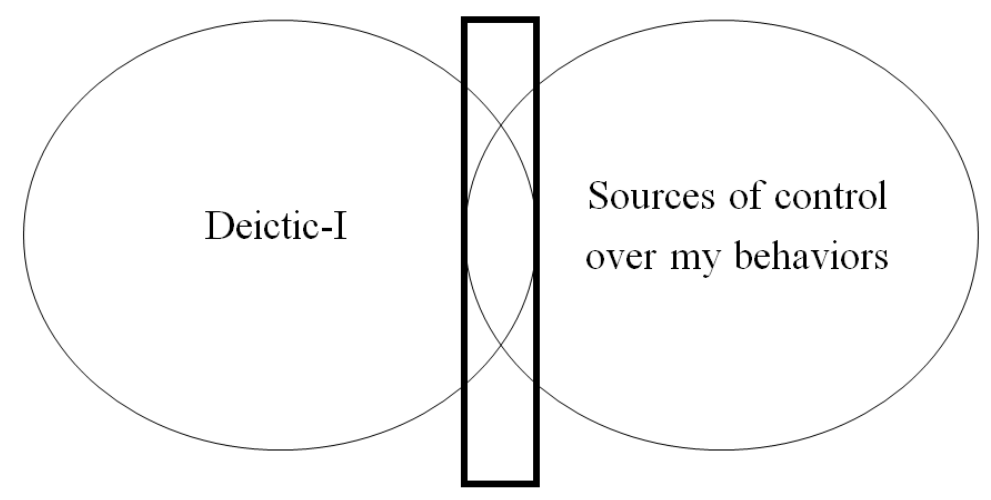

Figure 1. Verbal tracking of the sources of control over behavior.

Consider an individual who feels angry after a bad day at work and tells herself on such occasions that this is her partner's fault for not providing her in general with the life she wanted. This client's statement, for example, “I'm angry and it's all his fault" shows limited verbal tracking in that she does not seek to determine the more immediate cause of her anger on that occasion (i.e., a bad day at work). Indeed, perhaps for this client, most of her negative emotional reactions participate in hierarchical relations with her partner (most are attributed to him), and this strategy on her behalf has also led to a sense of lack of agency regarding

\footnotetext{
${ }^{2}$ In using the term verbal "track" or "tracking", we are not invoking the concept "tracking" as a type of rulegoverned behavior, as described in Hayes et al. (2001). Instead, we use tracking to refer to a client's ability to monitor the way in which their own behavior, including thoughts and feelings, is influenced by ongoing events in their environment. In this sense, tracking may be interpreted as broadly similar to what Villatte et al. (2015) refer to as "context sensitivity" (p. 53). We should add that we find neither concept (tracking or context sensitivity) entirely satisfactory and anticipate that we will replace "tracking" in due course by appealing to the dynamics of arbitrarily applicable relational responding, as articulated in a multi-dimensional, multi-level framework (i.e., the MDML) presented in the current volume (Barnes-Holmes, Barnes-Holmes, Luciano, \& McEnteggart, in press).
} 
directions she wants for her own life (e.g., she may say "he stops me from doing things I want") and feelings of resentment, inadequacy, and frustration. As a result, the client persists in keeping all of these emotions to herself, rather than sharing them with her partner. The therapist might engage with this client in a verbal functional analysis of these ongoing emotional experiences by exploring the range of possible labels (including "anger", "resentment", and "frustration") and the relational networks in which these participate. Ideally, therapy would lead to the client, in a similar situation, being able to say to herself " $I$ feel angry today, I'm not sure for now where this is coming from, so I must be careful not to take it out on my partner, but perhaps we could talk about it together".

In establishing verbal tracking of the causal relations between the emotional reactions of the deictic-I and other relational networks (e.g., a bad day at work), it also appears to be essential that these two sets of networks come to participate in a hierarchical relation (e.g., recognition that a bad day at work is just one of the many things that can happen to the deictic-I). Specifically, the networks of the deictic-I should contain the networks that relate causally to ongoing behavior. In simple terms, this enables the deictic-I to choose when, where, and with whom to behave in a particular manner. In the example above, the client could choose when to talk to her partner about her feelings and when not, because some of these emotional experiences relate to him directly and some do not. In this way, the therapist, using verbal functional analyses, aims to build broad and flexible relational repertoires with respect to choosing, so that the client (the deictic-I) is not a victim of capricious contextual variables, but gains a sense of control, if not over her environment, but over her reactions to it (for empirical analyses of hierarchical relational responding, see Foody, Barnes-Holmes, Barnes-Holmes, \& Luciano, 2013; Foody, Barnes-Holmes, Barnes-Holmes, Rai, \& Luciano, 2015; Gil, Luciano, Ruiz, \& Valdivia-Salas, 2012; Gil-Luciano, Ruiz, Valdivia, \& Suarez, 2016; Luciano, Rodriguez, Manas, Ruiz, \& Valdivia-Salas, 2009; Luciano, Ruiz, Vizcaino- 
Torres, Sanchez-Martin, Gutierrez-Martinez, \& Lopez-Lopez, 2011; Ruiz, Hernandez, Falcon, \& Luciano, 2016; Torneke, Luciano, Barnes-Holmes, \& Bond, 2016).

\section{The Therapeutic Relationship: The Drill-down}

At this stage, it seems important to emphasize that conducting verbal functional assessment and analyses typically involve building a strong therapeutic relationship, which should form a part of verbal functional analysis itself. For ease of communication, we cover this feature of therapy in a separate section, and use the metaphor of the drill-down to describe the therapeutic behaviors involved in this strategy.

The therapeutic aims of the drill-down involve building increasingly strong repertoires of relational responding between the deictic-I and what we describe as deictic-Others (i.e., loosely speaking, teaching the client to improve their perspective-taking skills).

Developmentally, the deictic-I is established in a shared and highly cooperative context in which significant others literally construct this verbal sense of self, with you and for you. Very young children, for example, often fail to distinguish themselves verbally from others, but gradually through verbal contingencies, they learn to talk about themselves as separate psychological entities, with private psychological worlds. When this 'shared' and 'cooperative' context with significant others in childhood contains high levels of what we call relational incoherence, the relationship between the deictic-I and deictic-Others, almost by definition, becomes unstable, unpredictable, and discontinuous (see Kohlenberg \& Tsai, 1991 for a similar approach on the formation of 'problematic selves').

For example, imagine a child who is told at one moment that she is loved and cherished by her parents and is then abandoned by them when they go on an alcoholic binge for days on end. Verbally, the relations among the deictic-I HERE and NOW are, by definition, rendered unpredictable and discontinuous in the sense that the "I" who was loved and cherished in one place and time was subsequently abandoned. When the coherence 
among the three elements of the deictic-I (I-HERE-NOW) is weakened in this way, the extent to which it can be used as a superordinate locus from which to relate hierarchically with all of the child's psychological events is severely undermined. In other words, for the I to function as a constant locus, from which to view one's psychological world, it must develop in a relationally stable and consistent environment. Critically, the absence of this type of environment may also fail to establish a deictic-I that is clearly verbally distinct from others. The individual who grows up in this type of environment may literally state in therapy years later "I have never really known who I am". For the client, this is not rhetoric or metaphor. This very statement is in the broad functional class of verbal relations in which they were raised as children.

When an individual grows up with a verbal history in which the relationship between the deictic-I and deictic-Others involved high levels of relational incoherence, the distinction between I-HERE-NOW and OTHERS-THERE-THEN may fail to emerge (McEnteggart, Barnes-Holmes, Dillon, Egger, \& Oliver, 2017). We have argued that the outcome of such a history may manifest itself in numerous ways. For example, a client may literally hear their own thoughts as the voices of others that are not actually present. Alternatively, clients may self-criticize using the phrases, and even the tone of voice, that their neglectful or abusive parents employed decades ago. Relationally, the voices and behaviors of others that were THERE and THEN are experienced as if they are HERE and NOW. Any attempt, in this type of context, to establish the deictic-I as a constant and separate (from others) locus would be difficult.

Our core argument is that the therapist needs to establish with the client a therapeutic relationship that provides the predictability and consistency (i.e., relational coherence with respect to the deictic-I) that were absent with significant others. This commences, in a sense, with the therapist attempting to provide the highly shared and cooperative verbal context in 
which a clearly distinct deictic-I is gradually established. This strategy is perhaps paradoxical because it starts by coordinating the deictic-I (the client) with the deictic-Other (the therapist). For example, a therapist at this point might say phrases like "I can completely understand that", "If I were you, I would have done exactly the same", "I can see how lonely you must feel", and "Anyone in your situation, would react that way". This can be a highly challenging therapeutic context for the client, but also for the therapist. It is challenging for the client because many of the overarching functional classes of behavior (such as disclosing private events, being vulnerable, accepting another person's perspective and potential disapproval) that were present in perhaps a highly aversive and threatening family environment may be evoked in therapy. It is challenging for the therapist because they must provide the stable, consistent, and reliable relationship that the client missed out on to this point. Indeed, experienced therapists are often noted for their abilities to 'absorb the perspectives of their clients' in a rich and full way (i.e., without pulling back, or being reactive or defensive). In a sense, the therapist seeks to establish specific contextually controlled coordinate relations that always remain relationally coherent between the client's deictic-I and the therapist's deictic-I, the purpose of which is to build trust and a sense of safety for the client in the therapeutic relationship. We are not suggesting that there is full coordination between I and Others (therapist and client). Rather, the therapist must, to some extent, see what the client sees, feels, etc., but always within the context of hierarchical relational responding from the therapist's deictic-I.

Central to the therapeutic relationship is the establishment of a relational repertoire in which the client learns to relate the deictic-I located HERE-NOW to the deictic-I located THERE-THEN. Metaphorically speaking, the therapist is taking the client by the hand and sharing with them how it is possible to talk about the deictic-I in different ways. The therapist may achieve this by coordinating the therapist's deictic-I and the client's deictic-I (both 
located HERE and NOW), so that they, metaphorically speaking, share their perspectives in a cooperative way on the client's deictic-I as located THERE and THEN. All events, including the client's deictic-I located THERE-THEN now become, if only momentarily, an 'it', an 'event', or a 'something', that is separate from both the client and the therapist as coordinated deictic-Is located HERE-NOW. In other words, the client and therapist sit together and develop a perspective on the client's sense of self as an event or object that can be observed and talked about, in a variety of ways.

As argued above, the drill-down is intertwined with verbal functional analyses. Specifically, the drill-down focuses on relational processes that appear to be central to what is often called the therapeutic alliance (see also Kohlenberg \& Tsai, 1991). For us, the drilldown metaphor works as a way of describing how we use the therapeutic relationship to 'dig deeper' in a verbal functional sense into the self (we often say "drilling down into the deictics"). For example, a verbal functional assessment might identify 'shame' as a critically important verbal stimulus for a client. In doing so, verbal functional analyses allow the therapist to assess the therapeutic relationship itself. A concrete example of this might involve the therapist asking the client if they are willing or ready to explore the impact that the word "shame" has on the client when uttered by the therapist. An affirmative response from the client sets the scene for further verbal functional analyses. For example, the therapist might sit next to the client and say "If I was you, I would have shame too". The important point to recognize here is that verbal functional analyses and the drill-down are dynamical in that they should ebb and flow with each other in the course of therapy.

We fully recognize that training therapists to master the highly dynamical interplay between verbal functional analysis and the drill-down may be challenging. In line with RFT itself, it seems that an appropriate method for successful training in this regard is to provide 
multiple exemplars of case supervision that involved this dynamical interplay. In the second half of the current paper, therefore, we present two such exemplars (i.e., case summaries).

\section{SUPERVISED CASE SUMMARIES}

This latter half of the paper comprises two case summaries in which verbal functional analysis and the drill-down featured strongly in case formulation and clinical focus. At the time of writing, both cases were incomplete, but the focus on the two key strategies is clear.

\section{Case Summary 1: Adult with Paranoia}

\section{Functional-analytic Approaches to Paranoia}

Recent approaches to paranoia, from a functional-analytic perspective (e.g., Stewart, Stewart, \& Hughes, 2016) and within ACT (e.g., Oliver, Joseph, Byrne, Johns, \& Morris, 2013) have focused on sufferers' reactions to their own experiences. For example, there is evidence that experiential avoidance mediates, at least in part, the relationship between early developmental experience and paranoia (Udachina, Varese, Myin-Germeys, \& Bentall, 2014). In short, the impact of a paranoid experience may depend upon how the individual reacts to it, such that attempting to avoid the experience potentially makes its occurrence in the future more (rather than less) likely, more frightening, and more believable.

\section{Referral Circumstances}

Marie was in her mid-40s when she first attended a community psychosis service in the United Kingdom (UK). She was referred after a brief hospital admission for anxiety and paranoia experienced in public. She reported frequent threatening "incidents" in which members of the public (usually male) looked at, or gestured to her in an unusual or ambiguous manner. These events made her feel extremely anxious and she typically responded by leaving the situation or occasionally confronting the individual. The perception of these incidents commenced several years earlier following a burglary at her apartment, and a

\footnotetext{
${ }^{3}$ Speech marks indicate client's own words throughout.
} 
mugging against her that occurred shortly thereafter. Because of her anxiety and hypervigilance to threat cues in public, Marie had become isolated and withdrawn, with only sporadic contact with several friends and with her family who lived in a different city.

Marie concluded that the various incidents represented an organized conspiracy (among local men, including a particular neighbor) to threaten, imprison, or kill her. Although puzzled by this possibility at first, she concluded across time that the conspirators must see her in an extremely negative light, such as depraved, like a "witch or a pedophile". She believed that drawing attention to herself in public always led to this type of negative perception of her by others. For example, on a recent bus journey, Marie experienced a sexual response to the close presence of a teenage girl. Because she caught the girl's eye, Marie immediately became fearful that other teenagers nearby believed her to be a "predatory lesbian pedophile”.

After events such as those concerning the teenager on the bus, Marie typically withdrew from going out in public for an extended period in an attempt to protect herself and to try to make sense of these experiences. These periods of withdrawal were associated with low mood, and difficulties in maintaining social contacts and routine activities, particularly employment. This pattern culminated in her quitting her local government job to go travelling for several months. During her travels, her mood improved and her anxiety lessened, but upon her return, her perception of threatening incidents recurred and rendered her unable to look for work. During this period, she felt extremely low and isolated, and this eventually precipitated her hospital admission.

Marie described a deep sense of loneliness and despair as her situation seemed to worsen. She could not see how to prevent further psychological deterioration or social isolation, or to move herself forward in life. Specifically, she felt utterly worthless at being single and unemployed, and worried a great deal about her family's critical judgements of her 
in these regards. At times, she also felt "disgusted" with herself and recalled similar feelings from her early childhood.

Her goals for therapy were to develop coping strategies to manage the anxiety associated with threatening incidents. She wanted in time to return to work and increase her circle of friends. Although she seemed highly convinced of the reality of her experiences, her help-seeking behavior suggested some variation in her levels of conviction in this regard.

\section{Early History}

Marie was born in a rural area in Asia. She had two older brothers. Although she described her parents as uneducated and very traditional, the family emigrated to the UK for stable factory work when she was aged two. Here, they continued to live within a tightly-knit Asian community with similarly-employed families. Marie's relationship with her parents was distant and one in which she felt "unrecognized". She recalled childhood incidents that confirmed her lack of value to them and contrasted starkly with the value they placed upon her brothers. She broadly recognized as an adult that elements of this differential treatment were cultural.

Marie's early enjoyment of various activities and sports also contrasted with her parents' narrow perception of her primary domestic duties, especially looking after familial males. She recalled that her own needs were disregarded and that she felt "like a piece of furniture, rather than a person". In addition, her family was heavily dominated by her grandfather, who was also influential within the wider community. The family (especially Marie) all feared this individual who was extremely punitive and controlling. She recalled a number of harsh and cruel incidents between the grandfather and various family members, against which both of her parents seemed powerless.

These childhood family circumstances contrasted sharply with early adulthood when Marie went to university against her parents' wishes (at that time in the UK attendance at 
third-level education was entirely supported by the State). This was a significant period in her life when she flourished and enjoyed a very active social life. During this period, she was able to renegotiate aspects of her relationship with her parents and became much closer to her mother, although they did not speak at that time about her painful early experiences.

\section{Verbal Functional Assessment}

Our aim in this section is to illustrate the verbal functional assessment undertaken with Marie and how we used this to conceptualize her case in a manner that would then facilitate therapeutic intervention including ongoing verbal functional analyses and the drill-down.

Inability to verbally track sources of behavioral control. At the beginning of therapy, Marie was almost completely unable to verbally track the sources of control over her behavior. For example, she reported that she didn't like older men who wore dark glasses, but could not explain why. In a sense, Marie was highly emotionally unstable and reactive, but was often confused about the source of these emotions.

Multiple deictic-Is. Marie's inability to verbally track the networks that controlled her behavior appeared to perpetuate the lack of an overarching sense of a unified self. Indeed, after some time in therapy, it appeared that she vacillated from one pattern of deictic-I responding to another (hence, these were not organized into overarching coherent relational networks). In short, verbal functional analyses appeared to reveal what we referred to as two largely separate networks of deictic-Is.

The first deictic-I relational network we labeled as 'deictic-I as victim'. In this, Marie perceived herself to be a victim of a threatening plot by (mostly older) men in her vicinity. For this deictic-I, Marie's actions were strongly controlled by paranoia and fear, which she 'dealt with' by concluding that she deserved the violent reproaches of others. Although elements of this deictic-I network were aversive, other elements were appetitive because it explained for Marie her fear of others and need for withdrawal in the interests of self- 
protection, hence no confusion was experienced in how she should act in a given situation, nor in terms of how others were perceiving her (i.e., she was sure they were horrified by her).

In contrast, the second deictic-I was judgemental, negative, harsh (e.g., "I am”... "worthless", “weak", and "bad"), and even extreme (“I'm depraved"). In this network, Marie perceived herself as a type of dangerous perpetrator (a "pedophile") who posed a risk to others (this is how she described the incident with the teenage girl on the bus). Hence, when responding as 'deictic-I as perpetrator', Marie reacted to deictic-Others (especially young females in close proximity to her) as her potential 'victims'. Verbal functional analyses suggested that, for Marie, this was the less aversive deictic-I network because Marie talked about herself in this way regularly and openly. It is also important to emphasize that when Marie was responding as deictic-I as victim, there was an almost complete lack of transfer of functions from this network to the deictic-I as perpetrator network, or vice versa. More informally, there appeared to be no relationship at all between the two deictic-Is. Hence, it was practically impossible, early on, for the therapist and the client to track the contextual variables that determined the almost complete dominance of one deictic-I network over the other.

Vulnerability in relating deictic-I as victim-HERE and NOW with deictic-I as victim THERE and THEN. As noted above, Marie's deictic-I as victim appeared to have appetitive functions (because as a victim she knew how to behave). On balance however, she was unable to verbally track the influence of her childhood trauma on her current paranoia. Thus, the therapist made statements such as: "It seems to me that you are just as much a victim now as you were when you were young". More technically, the aim was to establish a deictic-I as victim THERE and THEN that was causally related to the deictic-I as victim HERE and NOW. Marie reacted negatively to these statements and indicated that she felt highly vulnerable, unsafe, and unsure about how to react. She tended, by contrast, to focus 
heavily on the injustice of her past trauma. It became clear at this point that therapy needed to focus on the therapeutic relationship in terms of coordinating Marie's deictic-I as victim HERE and NOW with the therapist's deictic-I HERE and NOW, in approaching Marie's deictic-I as victim THERE and THEN. The reader should note, therefore, that sometimes when working with $\mathrm{S}+$ networks (in this case, Marie as victim), important aversive elements may be identified unexpectedly and thus, as mentioned earlier, the therapist needs to ebb and flow between verbal functional analyses and the drill-down.

\section{Therapeutic Directions Based on Verbal Functional Assessment}

The drill-down. In establishing the therapeutic relationship, the therapist focused continually on providing Marie with a safe, highly shared, and cooperative therapeutic environment. Marie appeared to find this emphasis on safety and sharing with a male therapist highly challenging to begin with. Nevertheless, the target in therapy was to gently coordinate Marie's deictic-I with the therapist's deictic-I, using many, many phrases, such as "I can completely understand that" and "That sounds terrifying”, even when discussing Marie's more paranoid perceptions (i.e., the conspiracy against her). Consider the following statements discussed in supervision as a format for the drill-down.

If I were you in such a situation, I would have felt utterly alone, unwanted, and unloved. I'd like you to help me understand this here. I want to get a sense of the things you say about yourself to yourself. I'm so glad you told me. That must have been so hard. It's so good to share this kind of thing. Notice that I am still here, and sharing this is OK.

In working on the therapeutic relationship, the therapist sought to coordinate Marie's deictic-I as victim HERE and NOW with the therapist's deictic-I HERE and NOW in order to establish a causal relation between Marie's deictic-I as victim HERE and NOW and deictic-I as victim THERE and THEN. More informally, the purpose was to help Marie to learn to verbally track the influence of past trauma on current paranoia. In this particular case, the therapist first focused on coordination between the two deictic-I as victim networks (HERE 
and NOW and THERE and THEN), with many questions such as "You must have been so lonely as a child? You must still be so lonely now?" This initial focus on coordination was necessary because Marie found it difficult to even see a connection between these two aspects of deictic-I as victim, and thus it would have been difficult to move on to causality and verbal tracking. Indeed, this focus on coordination marked a critical turning point in therapy and greatly facilitated Marie in learning to verbally track the influence of her past trauma on her current paranoia. Thereafter, the therapist was quickly able to establish a hierarchical relation with regard to deictic-I as victim, such that Marie could choose to act even when she felt paranoid and victimized (e.g., by encouraging her to leave the house to get shopping even when she had seen a neighbor who she perceived to be threatening in the street earlier that day).

Once verbal tracking in deictic-I as victim networks was established, the therapist began to explore the more aversive deictic-I as perpetrator network. Therapy focused on enabling Marie to verbally track the variables that evoked perpetrator-related behaviors (e.g., when a stranger's glance was interpreted as suspicion that she may be a pedophile). The therapist then introduced elements of hierarchy by exploring ways in which Marie could choose to act even when she experienced shame or paranoia that others had detected her perceived guilt. For example, after the bus incident with the teenage girl (described earlier), we explored the numerous possibilities of how the girl and her friends perceived the experience. The therapist then discussed the fact that Marie could choose to act based on her own choices and not based on the many possible interpretations others could have had about their experiences with her.

Having begun to explore both deictic-I as victim and deictic-I as perpetrator, we started to establish distinction relations between these two as a move towards ultimately establishing hierarchical responding over both networks. Consider the following statement 
suggested to the therapist during supervision, and designed to relate the two networks for the first time.

I can see how you can feel like a wicked perpetrator in one moment and yet be frightened and victimized the next.

When verbal tracking of the sources of control over Marie's behavior as both deictic-I as victim and as perpetrator was established, the therapist began to focus specifically on contexts that facilitated 'switching' from one deictic-I to the other. Only by doing so, could the therapist create a singular overarching hierarchical deictic-I who could choose to act. This was achieved by asking Marie across several sessions to identify which deictic-I was dominant: presently, five minutes ago, at the beginning of the session, yesterday, etc. We explored many such exemplars, including the numerous functions attached to each of the two deictic-Is. Indeed, the therapist identified several points in session when Marie appeared to "switch" from one deictic-I to the other. For example, when discussing how Marie's potential victims are not real victims (because she never had, and in her own view never could, actually inflict harm on another human being) Marie would often "switch" from perpetrator to victim. The therapist discussed these switches openly, and highlighted for Marie ways in which she could respond hierarchically from a stable and consistent deictic-I that could track the 'switching' itself, without either network controlling her behavior. At the time of writing, therapy continued with Marie in working towards establishing a stable and consistent deictic-I that contained the two deictic-I relational networks that we have labeled 'victim' and 'perpetrator'.

\section{Case Summary 2: Minor in Care}

\section{A Functional-analytic Approach to Children in Care}

'Looked after children' (LACs) are removed from their familial homes, at least temporarily, and placed in care (Department for Education, 2015), and many are also 
categorized as needing protection from neglect (Bentley, O’Hagan, Raff, \& Bhatti, 2016).

Numerous treatment paradigms have attempted to address the emotional and behavioral

difficulties that accompany living in care, and some of these appear to be functional-analytic in orientation (e.g., Prather \& Golden, 2009), but at the time of writing the ACT literature on working with children in care was limited (but see Hayes \& Ciarrochi, 2015).

\section{Referral Circumstances}

Charles was 15 years old when he was referred to a local child and adolescent mental health service in the UK. The referral resulted from the teenager expressing thoughts of selfharm and suicidal ideation to a schoolteacher, and the school raising broader concerns about the teenager's care. As part of the Local Authority's subsequent investigation, Charles allegedly stated that he should be taken into care because his mother's substance misuse rendered her unable to care for him. There were reports that his biological mother had been a 'functioning' opiate user for 20 years, and that his father experienced substance misuse and mental health issues. Following the investigation, Charles was placed on a Child Protection plan under the category of neglect, and his mother agreed to a voluntary placement order with a foster carer. He lived predominantly with a highly experienced foster mother, but continued to see his biological mother on a weekly basis. At the beginning of therapy, Charles had been in care for eight months. The lead therapist who undertook the therapeutic work with Charles became involved as part of the local authority referral to the Child and Adolescent Mental Health Service. Additional information was made available from Charles' key worker and an adolescent psychotherapist's report highlighting key issues. The therapist conducted a total of seven sessions with Charles' in his role within the Child and Adolescent Mental Health Service.

\section{Early History}


Part of the local authority investigation queried the possibility of in-utero brain damage resulting from maternal drinking and heroin use, but there was no medical evidence to support this. In addition, there was no evidence of developmental disability or delay. Charles' biological mother reported that he had been head-banging since birth, and wore a helmet to prevent injury. However, no head injuries or loss of consciousness had been reported.

Charles is an only child. His parents apparently separated when he was eight years old, although he could not recall ever living alone with his parents as a family unit. $\mathrm{He}$ subsequently described moving home often. He had lived with both sets of grandparents at various stages, but finally lived alone with his mother when he was 13 . He had always had close proximity to extended family on both sides. Charles' mother was described as "quiet". Although reported as a somewhat neglectful parent, Charles emphasized that she "respected my space". He spoke very rarely of his father, occasionally describing him as "a nobody".

Charles' paternal family were of mixed Asian heritage, although Charles had spent all his life in the UK. The maternal grandfather is believed to have long-standing involvement with organized crime and had a dominant role in the family. Charles' father was also reportedly involved in organized crime as a result of involvement with his 'father-in-law'. Charles' maternal uncle frequently collected him from his mother's house, drove him around, and gave him money and gifts, all of which were referred to by Charles as among numerous "family secrets". For example, Charles' mother forbade him from telling his father's side of the family that he was in care (hence, he could not be driven home by them to the foster home).

School. There had been sporadic school reports that Charles head butted and punched walls, usually after being teased by peers. Several such incidents were reported shortly before he was placed in care. Charles appeared to be managing academically. However, given that 
academic success is highly valued in his familial culture, he felt ongoing pressure in this regard (he stated that he was the most "stupid" of his cousins and was "not good at maths").

On balance, he liked creative activities and recognized his own achievements in drawing, art, and cooking. He reported feeling culturally isolated at his school, a sense of loneliness that was exacerbated by being in care.

\section{Verbal Functional Assessment}

Inability to verbally track sources of behavioral control. The deictic-I relational network for Charles was coordinated strongly with being in care. Being in care had many negative evaluative functions and these functions transferred to the deictic-I in the sense that Charles would say “Only bad stuff can happen to me because I'm in care”. Critically, however, Charles showed little verbal tracking of the impact of these negative evaluative functions on his behavior. For example, he did not connect his aggressive outbursts at school to being in care.

Early in the verbal functional assessment, it became clear that the more appetitive relational network for Charles involved anger (i.e., toward himself and others, particularly adults), hence the therapist strenuously steered away from adult-like instructive or pedantic dialog. This was often done with questions such as "You tell me what you think?" and I'm not sure about that, what would you say about it?" Consistent with our previous examples, the drill-down thus involved gently coordinating Charles' deictic-I with the therapist's. This was bolstered by some non-specific disclosing by the therapist and statements such as those below which were discussed in supervision.

If I was in your shoes right now, having experienced all that you have gone through, I would also be feeling the same way. I can see that this is so difficult for you. I can see the pain on your face. No-one seems to be really listening to your views. People are offering you solutions, giving you advice, but I promise, in here, I will totally listen to your views. I know when things have been out of control in my own life, I find them very scary. But it also makes me incredibly angry, and I often don't know why I'm angry, I just know that I am angry and I can't see how it would be any other way. 
During the drill-down, using the types of statements above, Charles started to cry, but did not become angry. As a result, the therapist gently introduced the word "vulnerable" and it immediately became clear that the functions of the word were extremely aversive. Indeed, when the word was first introduced, Charles quickly fell asleep, thus literally avoiding the therapeutic interaction. Initially when this occurred, the therapist allowed Charles to sleep for around 20 minutes before gently waking him.

\section{Vulnerability in relating deictic-I HERE and NOW with deictic-I THERE and}

THEN (future). As noted above, the relational network containing 'anger' appeared to have appetitive functions, but the network in which 'vulnerability' participated had predominantly aversive functions. The therapist used the drill-down to gradually decrease avoidance responses to 'vulnerability' by focusing initially on 'anger'. In doing so, Charles talked at length about the future (e.g., "I can't see my future will ever be happy", "I watch films and see happy endings and wonder whether that will be for me", and "I look at Facebook and see friends from the past looking really happy and I envy them. They are at the next level [of life's game] whilst I am stuck on this [unhappy] level. I wish I could be like them”). The therapist interpreted this as avoiding the aversive functions of vulnerability in the present by focusing on the future. In the ebb and flow between verbal functional assessment and the drill-down, the therapist used statements such as the following, as discussed in supervision, to help undermine avoidance of the present by focusing on the future.

What I often notice when you come into our sessions is that life is tough for you at the moment. You seem tired and you see others as having it much easier. Perhaps most do at present. I noticed that you were speaking about how you watch a film, and there always seems to be a happy ending, and I see how you compare yourself with this. Yet here you are now, coming to talk to me about these frustrations, opening up to me, someone you don't really know. I also see that despite all this, you are still going to school now.

Relating his biological and foster mothers as deictic-Others. Having helped

Charles begin to talk about both anger and vulnerability, thereby undermining the avoidance 
functions of these stimuli in the present (i.e., for the deictic-I HERE and NOW), the therapist continued to focus on both (anger and vulnerability). This strategy was adopted because Charles started to talk for the first time about his biological mother (whom he refused to talk about initially). In spite of her neglect, Charles spoke positively about his biological mother (e.g., he continually emphasized the fact that she "gave me space"), and yet he spoke harshly about his foster mother who provided him with a warm, caring environment ("I can't cope with the current situation. This is worse than the drug stuff. [I'd] rather be in a family hunted down by gangs than be in this house"). This issue concerning the two maternal figures was explored in supervision and the following questions were posed to the therapist to consider.

How does he describe the key relationship with his mother? What does he say about his relationship with the foster mother? It seems as if he somehow connects the two mothers together? Is there any sense in which the two mother figures could be opposites? Would you say that the more attentive the foster mother is, the more he rejects her?

Subsequent verbal functional analyses during therapy indicated that Charles did indeed relate the two maternal figures in opposition to each other. That is, when positive functions were attached to the foster mother (e.g., when she was kind to him) he found this highly aversive, because this established negative functions for his biological mother. The paradoxical aversiveness of the caring foster mother relative to the biological mother's neglect became the focus of ongoing therapy.

\section{Therapeutic Directions based on Verbal Functional Assessment}

At this point in therapy, several sessions had been devoted to conducting the functional analyses that permitted our understanding of the relations between the two mothers, and thus we had little remaining opportunity to address this issue in terms of intervention. Nevertheless, the therapist's initial attempt to do so involved the following statements, as discussed in supervision.

You seem often to be angry towards your foster mother? And I noticed how you often highlight how she is different from your mum, including how she is often asking you to do stuff, and not giving you any peace and quiet. Is that different from how your mum was towards you? 
When these statements were emitted by the therapist, Charles was invariably non-responsive, although at this point in therapy he was engaging with the therapist actively in many other areas. The therapist, therefore, used the strong therapeutic relationship that had been established with the drill-down to gently encourage Charles to talk about the two mothers comparatively, with a particular focus on how he was reacting to them. The overarching purpose here was to begin to establish verbal tracking of the sources of control over his behavior in the context of comparing the two mothers. At this point in therapy, the therapist no longer had access to Charles because he was moved to a different part of the social services system, which is standard practice and did not reflect upon the therapy that was undertaken with Charles.

\section{General Conclusions}

In the first half of the current article, we aimed to provide an RFT-based account of the verbal functional analyses that characterize the way we have come to do therapy. The therapy itself, and the ways in which we have sometimes talked about it, could not be considered strictly-speaking a purely bottom-up approach in the sense that they were derived from RFT and nothing else. However, in our view, the therapeutic work has remained closely connected to RFT and we continue to strive to build those connections further. Indeed, this very article is an example of that aspiration. As we continue this work, it will be important to further expand the conceptual links with recent developments in RFT, such as the MDML framework (presented in this volume) for analyzing relational responding. Equally, it will be important to connect the RFT analyses presented in this paper with the therapeutic work that is conducted with actual clients.

In an effort to show how this might be done, the second half of the current paper attempted to illustrate the close integration between RFT-based analyses and clinical intervention directed by these in a case study format. Specifically, we employed the concepts 
of verbal functional analysis and the drill-down to guide both our case formulations and therapeutic intervention. The two cases selected were intentionally complex and diverse to show that these concepts at essence are functional-analytic and thus applicable to all aspects of verbal psychological suffering. While neither case reached clinical completion at the time of writing, it seemed wise to begin to share the excitement and positive change the therapists experienced in both clients, and the clinical precision offered by these RFT-based concepts. 


\section{References}

Barnes-Holmes, D., Barnes-Holmes, Y., Hussey, I., \& Luciano. C. (2016). Relational frame theory: Finding its historical and intellectual roots and reflecting upon its future development. In R. D. Zettle, S. C. Hayes, D. Barnes-Holmes, \& A. Biglan, T. (Eds), The Wiley handbook of contextual behavioral science (pp. 115-128), West Sussex, UK: Wiley-Blackwell.

Barnes-Holmes, D., Barnes-Holmes, Y., Luciano. C., \& McEnteggart, C. (in press). From the IRAP and REC Model to a Multi-Dimensional Multi-Level framework for analyzing the dynamics of arbitrarily applicable relational responding. Journal of Contextual Behavioral Science (Special Issue on Relational Frame Theory).

Bentley, H., O’Hagan, O., Raff, A., \& Bhatti, I. (2016). How safe are our children? London: National Society for the Prevention of Cruelty to Children (NSPCC).

Department for Education. (2015). National Statistics. Children looked after in England including adoption: 2014 to 2015.

https://www.gov.uk/government/uploads/system/uploads/attachment_data/file/46475 6/SFR34_2015_Text.pdf

Foody, M., Barnes-Holmes, Y., Barnes-Holmes, D., \& Luciano, C. (2013). An empirical investigation of hierarchical versus distinction relations in a self-based ACT exercise. International Journal of Psychology and Psychological Therapy, 13(3), 373-388.

Foody, M., Barnes-Holmes, Y., Barnes-Holmes, D., Rai, L., \& Luciano, C. (2015). An empirical investigation of the role of self, hierarchy, and distinction in a common act exercise. The Psychological Record, 65(2), 231-243.

Gil, E., Luciano, C., Ruiz, F. J., \& Valdivia-Salas, S. (2012). A preliminary demonstration of transformation of functions through hierarchical relations. International Journal of Psychology and Psychological Therapy, 12(1). 
Gil-Luciano, B., Ruiz, F. J., Valdivia, S., \& Suárez, J. C. (2016). Promoting psychological flexibility on tolerance tasks: framing behavior through deictic/hierarchical relations and specifying augmental functions. The Psychological Record, 66, 1-9.

Hayes, L., \& Ciarrochi, J. (2015). The thriving adolescent: Using acceptance and commitment therapy and positive psychology to help young people manage emotions, achieve goals, and build positive relationships. Oakland, CA: Context.

Hayes, S. C., Strosahl, K., \& Wilson, K. G. (1999). Acceptance and Commitment Therapy: An experiential approach to behavior change. New York: Guilford Press.

Hayes, S. C, Strosahl, K. D., \& Wilson, K. G. (2012). Acceptance and Commitment Therapy: The process and practice of mindful change (2nd edition). New York: Guilford.

Kohlenberg, R. J. \& Tsai, M. (1991). Functional Analytic Psychotherapy: Creating intense and curative therapeutic relationships. New York: Springer.

Luciano, C., Rodríguez, M., Mañas, I., Ruiz, F., \& Valdivia-Salas, S. (2009). Acquiring the earliest relational operants: Coordination, distinction, opposition, comparison, and hierarchy. In Rehfeldt, R. A. \& Barnes-Holmes, Y. (Eds.) Derived relational responding: Applications for learners with autism and other developmental disabilities: A progressive guide to change (pp. 149-172). Oakland, CA: New Harbinger.

McEnteggart, C., Barnes-Holmes, Y., Dillon, J., Egger, J., \& Oliver, J. (2017). Hearing voices, dissociation and the self: A functional analytic perspective. Journal of Trauma and Dissociation, 18, 575-594.

Oliver, J. E., Joseph, C., Byrne, M., Johns, L. C., \& Morris, E. M. (2013). Introduction to mindfulness and acceptance-based therapies for psychosis. In E. M. J. Morris, L. C. Johns, \& J. E. Oliver (Eds), Acceptance and commitment therapy and mindfulness for psychosis (pp.1-11). Oxford: Wiley. 
Polk, K. L., \& Schoendorff, B. (2014). The ACT Matrix: A new approach to building psychological flexibility across settings and populations (Eds.). Oakland, CA.: New Harbinger.

Prather, W. \& Golden, J. A. (2009). A behavioral perspective of childhood trauma and attachment issues: Toward alternative treatment approaches for children with a history of abuse. International Journal of Behavioral and Consultation Therapy, 5(1), 56-74.

Ruiz, F. J., Hernández, D. R., Falcón, J. C. S., \& Luciano, C. (2016). Effect of a one-session act protocol in disrupting repetitive negative thinking: a randomized multiple-baseline design. International Journal of Psychology and Psychological Therapy, 16(3), 213233.

Stewart, C., Stewart, I., \& Hughes, S. (2016). A contextual behavioural approach to the study of (persecutory) delusions. Journal of Contextual Behavioral Science, 5(4), 235-246.

Strosahl, K. D., Robinson, P. J., \& Gustavsson, T. (2012). Brief interventions for radical change: Principles and practice of focused acceptance and commitment therapy. Oakland, CA: New Harbinger.

Torneke, N. (2010). Learning RFT: An introduction to relational frame theory and its clinical application. Oakland, CA: New Harbinger.

Törneke, N., Luciano, C., Barnes-Holmes, Y., \& Bond, F. W. (2016). RFT for clinical practice: Three core strategies in understanding and treating human suffering. In R. D. Zettle, S. C. Hayes, D. Barnes-Holmes, \& A. Biglan, T. (Eds), The Wiley handbook of contextual behavioral science (pp. 254-272), West Sussex, UK: Wiley-Blackwell.

Udachina, A., Varese, F., Myin-Germeys, I., \& Bentall, R. P. (2014). The role of experiential avoidance in paranoid delusions: an experience sampling study. British Journal of Clinical Psychology, 53(4), 422-432. 
Villatte, M., Villatte, J. L., \& Hayes, S. C. (2015). Mastering the clinical conversation: Language as intervention. New York: Guilford. 